\title{
A CAMPO ABIERTO: WALTER BENJAMIN Y LA NATURALEZA
} In open field: Walter Benjamin and nature

\author{
JOSÉ MARÍA DE LUELMO JAREÑO \\ Universitat Politècnica de València (España) \\ jolueja@pin.upv.es
}

Resumen

Si bien el interés del filósofo Walter Benjamin por el espacio urbano viene motivando desde hace tiempo estudios y análisis exhaustivos, no sucede otro tanto con sus numerosas reflexiones sobre el espacio natural. Tratando de suplir esta carencia, el artículo toma como núcleo un corpus de escritos del autor que dan cuenta de ese interés -fragmentos ensayísticos, relatos breves, diarios, correspondencia- con el fin de evaluar las variables filosóficas que se manifiestan en el contacto del pensador alemán con el paisaje y la manera en la que los escenarios naturales acogen y determinan su talante y su trayectoria personal.

Palabras clave: Walter Benjamin, naturaleza, paisaje, caminar

Abstract

Although the interest of the philosopher Walter Benjamin for the urban space has been motivating exhaustive studies and analysis for a long time, the same cannot be said of his many reflections on the natural space. Trying to fill this gap, the article takes as its core a corpus of writings by the author that account for this interest - essay fragments, short stories, diaries, correspondencein order to evaluate the philosophical variables that become evident in the contact of the German thinker with the landscape and the way the natural settings receive and determine his mood and his personal trajectory.

Key words: Walter Benjamin, nature, landscape, walking

\section{$[][]$.}

Acercarse al pensamiento de Walter Benjamin desde la perspectiva de su interés por los lugares constituye, en sí mismo, un lugar común. Un topos bien justificado, hay que decir, porque en palabras de Karl Schlögel "Benjamin dependía del lugar como ningún otro pensador, de él sacaba su fuerza, en él su mirada fisionómica volvía a cebarse, cobrar fuerzas y confirmarse una y otra vez" (2007, p. 131)". Destino y carácter-título de uno de sus ensayos- se habrían confabulado para que el componente espacial adquiriese un valor semejante: si por un lado las tensiones del periodo histórico que le tocó en (des)gracia le llevaron a reflexionar a fondo sobre la fisionomía y la relevancia del suelo propio y ajeno, "una cierta desazón y una insatisfacción interior frente a las circunstancias en que se desarrollaba su vida en tanto que homme de lettres", anota su amigo Gershom Scholem, "confluyen a la hora de explicar la gran cantidad de 


\section{José María de Luelmo Jareño}

direcciones y lugares de residencia" (1987, p. 134). Así lo constata, con especial elocuencia, la carta que desde la entonces ignota isla de Ibiza le remite el propio Benjamin en abril de 1932, es decir, poco antes de verse definitivamente abocado al exilio:

En el preciso momento en el que tú te diriges a las metrópolis europeas, yo me retiro a su rincón más alejado [...] esta era mi única oportunidad de escapar de la ignominia que en Berlín está regulando los salarios y las transacciones y que termina produciendo una tensión insoportable (Benjamin, 2008b, pp. 35 y 37).

Empujado a los márgenes de la Modernidad y, con ello, aislado tanto de su entorno vital como de su principal núcleo de interés y trabajo intelectual, la ciudad, Benjamin abandona contra su voluntad toda comodidad burguesa para ir a dar a un campo de fuerzas, la Naturaleza, con el que desde edad temprana habría mantenido una tensión irresuelta. Quizá baste con atender a esta experiencia, habida a los dieciocho años de edad en el curso de un viaje a la frontera entre Italia y Suiza, para ponderar una relación lastrada por la amarga discordancia entre deseo y realidad:

En algún lugar yo también tuerzo a un lado. Parece imposible ascender al camino del que acabamos de bajar. En los escalones arde el sol, como si las piedras fueran a deshacerse. Solo con esfuerzo puedo mantenerme en pie. Trepando con las manos, siempre estorbadas por el bastón, subo a lo alto. De pronto estoy ante una casa: aquí se acaba el camino. Por ningún lugar de toda la zona se ven seres humanos. Ahora doy la vuelta paseando sobre el estrecho muro de un viñedo y estoy resignado a caer abajo en cualquier momento. Pero quiero seguir avanzando hasta salir al espacio abierto que hay encima del pueblo y quizás poder llegar a la orilla por la pendiente. Así, pronto tengo también las casas detrás, y ante mí la pendiente. Suelo de hierba... pero tan empinado que no puedo caminar y tengo por fuerza que caer resbalando. Voy a parar a una plantación de viñedos que exploro hasta tropezar con una pequeña escalera que conduce abajo. Cuando quiero abalanzarme para descender por ella caigo agotado al suelo, siento después un segundo mareo y descanso tres minutos. Luego, escalera abajo, voy a parar a un callejón que cae sobre el lago... Allí, una pancarta, un restaurante en el que están sentados los demás (Benjamin, 1996, p. 103).

Además de ser buena prueba de su pobre capacidad física y de lo que él mismo denomina un "malísimo sentido de la orientación" (p. 190), el testimonio resulta característico del cariz instrumental -explorar el mundo sensible, ponerse a prueba- que el futuro filósofo concede a sus primeros pasos en la Naturaleza. Que Benjamin estimara lo natural como un escenario vital no tiene nada de excepcional, siendo como era norma en la cultura europea del cambio de siglo, pero sucede además que en el contexto alemán esa consideración de la Naturaleza poseía un doble significado, pues al hecho de servir 
de marco para la Bildung o realización individual sumaba el de acoger y promover la Gemeinschaft o realización colectiva, la comunión identitaria con "los demás", por emplear la expresión que cierra su relato.

Si la educación escolar de la época incorporaba de por sí todo tipo de actividades a la intemperie destinadas a fomentar los valores personales y la convivencia entre iguales sometidos a un fin común -recorrer distancias, alcanzar cotas, leer la Naturaleza-, el programa del Instituto Pedagógico de Haubinda, donde Benjamin permaneciera internado entre 1905 y 1906, incidía aún más en estos fines gracias a la iniciativa de su director, el prestigioso pedagogo Gustav Wyneken. Sin llegar al extremo de los Wandervogel, la agrupación excursionista más popular del momento, el sujeto-en-ciernes se veía en Haubinda arrojado al mundo natural, enfrentado a circunstancias de todo tipo y evaluado en consecuencia, de ahí la pesadumbre de Benjamin al arrastrar las carencias personales señaladas con anterioridad, a saber, impericia ["solo llevamos un pequeño mapa no muy detallado y una brújula, y después de andar un rato por el sendero no teníamos ni idea de donde estábamos"(1996, p. 70)]; y debilidad ["yo soy un mal caminante, y ya en Haubinda me daba un poco de miedo esta marcha" (p. 70)]. Los signos de esa desazón aparecen repetidamente en los apuntes de esos años, por ejemplo en abril de 1911, fecha en la que anota cómo "esta mañana arrastré mi cuerpo por los Seebachsfelsen hasta la Spiessberghaus, luego se me portó bien y subimos a su enmohecida cumbre" (p. 72), o días después, cuando tras algún que otro rapto de vigor ["un fortísimo espíritu de marcha me sobreviene" (p. 79)], se ve forzado a reconocer hasta qué punto "llego realmente cansado a la cumbre; con dificultad, tengo que reprimir las náuseas" (p. 82).

El bálsamo frente a tanto padecimiento vendrá de sus propios adentros y presentará un sesgo netamente racional, taimado incluso, como cuando sentencia que "estoy cansado y lo sé todo, pues ya he comprendido este paisaje y lo disfruto absolutamente" (p. 85). Más allá de la aparente suficiencia, al sostener que "lo sabe todo" y "ha comprendido" el paisaje Benjamin nos pone sobre la pista del segundo de los cometidos instrumentales que la Naturaleza adquiere en su formación, y uno determinante: servir como inspiración estética y levadura intelectual. Dado que la idónea formación del espíritu pasaba por apreciar las manifestaciones efímeras o estables del mundo natural y el sinnúmero de correspondencias que se tienden en su interior y acaban repercutiendo en el ser humano, ya sea de forma biológica, psicológica o moral, el joven Walter se esforzará, mal que bien, por abrazar ese ideal. Aunque sus primeras aproximaciones al medio se sirvan de un filtro protector netamente burgués ["siempre siguiendo el consejo de Spitteler: no mirando boquiabiertos a la Naturaleza, sino hablando sobre Berlín, el teatro, la corrupción del lenguaje” (1996, p. 72)], pronto se dejará llevar por las cualidades del paisaje, compartirá emociones con sus compañeros de fatigas ["trepamos por un macizo montañoso [...] que permitía tener una vista panorámica del Inselsberg y de un bonito valle boscoso; antes aún habíamos sido capaces de apartar la mirada, pero de aquí no podíamos irnos"(p. 75)], y comenzará a emitir 
juicios de valor sobre la Naturaleza, aunque un tanto elementales quizá para tratarse de un aspirante a filósofo ["nos encontrábamos en un espacio libre bordeado por peñascos, tan bonito que parecía una pintura" (p. 71)]. Haciendo buena la expresión, todo se andará, y el viajero Benjamin irá poco a poco cuajando su peculiar mirada fotográfica ["quiero apresar y guardar en mi interior toda la imagen, y sobre todo las montañas que ahora veo por última vez para mucho tiempo" (p. 91)] y, con ella, la conciencia de la enorme dificultad que comporta rendirla fielmente por escrito ["dejar constancia de estos sutilísimos fundamentos de diversas impresiones paisajísticas es difícil, y a veces, para algunos, imposible", apunta en su Diario de Wengen, de 1911 (1996, p. 80)]. Como tantos otros escritores antes y después de él, Benjamin se quedará sin palabras no por desconocimiento sino por insuficiencia y fragilidad del material, de ahí que acabe expresando menos la configuración de la escena que su calidad genérica ["el paisaje que hay detrás del Gotthard posee aún hoy [...] el carácter originario de una soledad profunda" (p. 96)], la emoción estética promovida por ella ["aquí la Naturaleza no está al servicio de la belleza, sino de una grandiosidad casi arquitectónica que por fuerza tiene que impresionar" (p. 95)], o su efecto acumulativo y global: "ninguna vivencia aislada se marcó con fuerza en la impresión conjunta de todo este viaje; naturaleza y arte culminaron simétricamente por todas partes en eso que Goethe llama solidez", deja anotado en otro de sus diarios, esta vez de 1912 (p. 93).

Aunque salta a la vista que sus escritos del periodo están guiados por un estilo recurrente, por un Romanticismo de manual, se hace necesario precisar que, a pesar de la angustia motivada por la referida carencia expresiva, y a pesar también del tono enfático y de las apelaciones a la "belleza", la "grandiosidad" o la "soledad profunda" del mundo natural, difícilmente puede caracterizarse a Benjamin como a un romántico al uso. No encontraremos en él signos de un dolor metafísico, o de una conciencia de la caída trasmutada en distanciamiento culpable, o una lectura esotérica de la Naturaleza, y no hallaremos nada de todo ello por la sencilla razón de que, en palabras de Marx que un Benjamin menos prudente habría suscrito, "la Naturaleza, tomada en forma abstracta, por sí, fijada en la separación del hombre, no es nada para el hombre" (Marx, 2005, p. 26). $\mathrm{Si}$ bien el materialismo benjaminiano salta a la vista en ciertos intereses que le acompañarán siempre [el valor concedido a la técnica, el afán coleccionista o la fascinación por la vida urbana], el contacto directo con la Naturaleza evidencia también ese patrón de pensamiento bajo la forma de un énfasis en la sensorialidad pura y una primorosa atención hacia el detalle que actúan en detrimento de las grandes resonancias y de la épica de los gestos. Es bien elocuente, en este sentido, la reflexión que suscita años más tarde, el 13 de mayo de 1931, su visión del paisaje provenzal:

Miro afuera, al paisaje: ahí está el mar en su bahía, brillante como un espejo; los bosques se extienden cual masa impasible y muda hasta la cima del monte; allá arriba, ruinas de murallas tal y como estaban ya hace siglos; el cielo sin nubes 
resplandece en un 'eterno azul', como se suele decir. Así lo quiere el soñador que se absorbe en este paisaje; que este mar suba y baje a cada instante en miles y miles de millones de olas, que los bosques vuelvan a estremecerse a cada instante desde las raíces hasta la última hoja, que en las piedras de las ruinas del castillo reine un ininterrumpido derrumbarse y gotear, que en el cielo bullan desordenadamente los gases enfrascados en una lucha invisible, antes de aglomerarse formando nubes; el hecho de que la ciencia observe este movimiento siguiéndolo hasta lo más íntimo de la materia y que en los átomos no quiera ver más que conjuntos de electrones, todo esto tiene él que olvidarlo, pretende negarlo para abandonarse a las imágenes en las que desea obtener paz, eternidad, tranquilidad, continuidad [...] Poner diques de este modo a la Naturaleza en nombre de imágenes descoloridas: esta es la magia negra del sentimentalismo (Benjamin, 1996, p. 152).

El sentimentalismo no es sino una distorsión de la evidencia, un filtro fatal, viene a decir Benjamin. A ojos de sus practicantes nada existe por sí mismo sino que se manifiesta retóricamente y en función de una dimensión suprema, circunstancia que conduce a dejar en suspenso lo inmediato y la mecánica de causas y efectos en beneficio de una arrulladora música que suena siempre bien lejos y al mismo tiempo, como en una caja de resonancia, bien adentro. Ese "abandonarse a las imágenes en las que desea obtener paz, eternidad, tranquilidad, continuidad" tomando la Naturaleza como pretexto no sería sino una versión edulcorada de la propedéutica que en su día urdiera la Naturphilosophie alemana, aquella disciplina que lejos de estar enfocada "a la superficie de la Naturaleza y a lo que es objetivo en ella, a su cara externa", como es el caso de la ciencia empírica, "apunta en general al impulso interno y a lo no objetivo de la Naturaleza”, en palabras del propio Schelling (1996, p. 123). Los románticos asimilaron esta premisa idealista, la llevaron a su terreno y consideraron que, si el vínculo entre individuo y Naturaleza se sostenía en una energía común, la verdadera conexión entre ambos únicamente podía articularse de manera interna, pues solo el paradójico Weltinnenraum ["el élan que fluye a través de la Naturaleza y brota, inter alia, en la voz interior", en definición de Taylor (1996, p. 392)] permitía anudar los cabos de una misma cuerda que la razón instrumental se había encargado de separar. De hecho, el giro introspectivo se les ofrecía como el único modo de rescatar el estado primigenio e ideal de la existencia, de aquel Ur-eine previo al logos cuya energía palpitaba todavía en los pliegues de la conciencia, como nos recuerda Alfredo de Paz:

Los románticos trataron de comprender la unidad profunda considerada como la única real; por tanto, trataron de buscar en nosotros todo aquello que puede sobrevivir de nuestras facultades antes de la separación. De este modo, cada experiencia se consideraba tanto más auténtica cuanto más pudiese ser considerada un vínculo para restablecer nuestra comunicación inicial con el universo divino, o la manifestación de un ámbito, más profundo que nosotros mismos, donde esta 
comunicación subsiste a pesar de la caída. De este modo, el hombre puede volver a ser dueño de sí mismo solo cuando reconquista el dominio de su propio misterio interior (1992, p. 62).

También persigue Benjamin lo originario y el dominio de sí mismo, pero con qué sentido y con qué procedimientos tan distintos a los del Romanticismo. El sustrato que yace al fondo del individuo y que el contacto con la Naturaleza viene a remover no es para él un material genérico y común a todo ser humano sino, antes bien, una latencia que apela al pasado específico y a la circunstancia particular de cada cual. Sabedor de que "lo original siempre se presenta como un descubrimiento que es al mismo tiempo un reconocimiento" (Benjamin, 1972, p. 938; trad. del autor), y un reconocimiento de uno mismo más que de una abstracta humanidad, un Benjamin recién llegado a la cuarentena dará en escudriñar entre sus recuerdos de infancia y abordará, al hilo de su inmersión en la Naturaleza ibicenca -tres meses en 1932 y seis en 1933-, una empresa memorialista que actuará a la vez como ontogénesis de su personalidad y motor de conciencia en un presente enturbiado.

Mucha atención se ha prestado al papel mnemotécnico del espacio urbano en ese empeño autobiográfico; casi ninguna al que cumple el espacio natural. Y sin embargo este es el caso: es la Naturaleza de la isla de Ibiza la que lleva a esa segunda Naturaleza que es la urbe, al espacio antropizado donde se gestó la memoria individual, de tal manera que solo con el concurso de aquella esta despierta de su letargo y sale al fin a colación. Cabe recordar que en octubre de 1931 Benjamin adquiere con la revista Literarische Welt el compromiso de entregar a imprenta una semblanza de la ciudad de Berlín en un plazo máximo de tres meses, un contrato clave para su subsistencia que será incapaz de cumplir pero que despertará en él la idea de redactar el texto de modo estrictamente personal. En esta coyuntura, la referida contigüidad entre marco físico y actividad mental permitiría explicar que fuera precisamente en Ibiza donde Benjamin diese en rescatar y fijar los recuerdos del Berlín de su infancia por distantes que fuesen los lugares de origen y destino y nula su aparente relación. Entre muchos otros que podrían citarse, acude en apoyo de esta conjetura un párrafo de su primera tentativa analéptica, Crónica de Berlín-redactada en Ibiza en la primavera de 1932-, donde ámbito urbano y ámbito natural se intercambian dinámicamente y la consabida torpeza se torna virtud:

No orientarse en una ciudad: esto quizás sea poco interesante y banal. Para esto se necesita desconocimiento... y nada más. Pero perderse en una ciudad -igual que uno se pierde en un bosque- es algo que requiere ya una formación muy distinta. Para ello, letreros y nombres de calles, transeúntes, tejados, quioscos y tabernas tienen que hablarle al callejeante como ramas que crujen en el bosque bajo sus pies, como el espantoso grito de un avetoro a lo lejos, como la súbita calma de un claro del bosque en cuyo centro un lirio ha brotado (Benjamin, 1996, p. 193). 
Tan satisfactoria le parecerá a Benjamin la imagen como para emplearla con algunos cambios y a modo de apertura en su segunda remembranza, Infancia en Berlín hacia 1900, escrita en el periodo que media entre sus dos estancias isleñas y por la que es conocida y ha hecho fortuna. Que la tenga en tanta estima viene a confirmar su valor funcional, este es, el de establecer analogías entre espacios antagónicos en virtud de la actividad idéntica que vienen a promover, pero si interesa referirla en este punto es por la circunstancia misma de su formulación, por el hecho de haber nacido al calor de ciertas experiencias (Erlebnisse) habidas en la isla que de un modo u otro removieron la trastienda de la experiencia personal (Erfahrung). Benjamin evoca el andar a la ventura justamente cuando el espacio en el que solía ponerlo en práctica le ha sido negado para siempre, y si así sucede es porque a pesar del tiempo transcurrido y del cambio radical de escenario la manera de caminar, mal que bien, se mantiene. De forma paradójica para un Benjamin que en principio llega a la isla para olvidar, el paseo a la ventura por ignotos parajes ["con toda seguridad los más inhóspitos y vírgenes que he visto en tierras habitables" (2008b, p. 51)] promueve el recuerdo de sensaciones pretéritas que en ocasiones son un correlato directo de las vividas en tiempo real:

Los jardines forestales de Glienicke, los anchos, festivos paseos del castillo de Babelsberg, el estrecho sendero oculto de nuestro jardín de verano, las umbrosas arcadas que bajaban al lago Griebnitz en los lugares donde había embarcaderos... Todo esto lo incorporé a mi reino y en un momento completé en la fantasía la obra de incontables paseos, juegos, vagabundeos (Benjamin, 1996, p. 241).

Al compás de los pasos uno y otro espacio dejan de ser por sí mismos y se iluminan mutuamente: el mítico paisaje mediterráneo que envuelve al caminante despierta resonancias de aquel mágico reino habitado en exclusiva por el pequeño Walter a las afueras de Berlín, y al revés, porque la memoria involuntaria remite a desplazamientos y vivencias de antaño pero transfigura además el espacio que ahora transita el caminante y las sensaciones a las que este da lugar. El ars memoriae basado en hitos donde algo aconteció de facto o algo fue funcionalmente ubicado cede ante una praxis dinámica que vincula lo inmediato y lo pasado no merced a correlaciones estrictas sino a afinidades electivas en las que el tertium comparationis se muestra, cuando menos, difuso, si bien en ocasiones adquiere cierta definición, como en el caso del paseo que motiva el relato titulado $A l \mathrm{sol}$, en cuyo transcurso la visión de un sauce trae a su mente "el día en que sintió con un árbol [...] apoyó la espalda contra un tronco, y el árbol le enseñó lo que sentía” (Benjamin, 2010, p. 369), o en una de las piezas breves que redacta en el mismo periodo, donde deja constancia de otro árbol, "un álamo o quizás un aliso", bajo el que se abandona hasta que "un suave viento aportó música a esta boda y llevó por el mundo, tal como en un lenguaje metafórico, a unos niños que ahora no tardaron demasiado en nacer" (pp. 375-376). Mucho hay de nostalgia en esta referencia a la infancia, algo también de amargura, y es que el goce 
de habitar el espacio no solo trae de la mano sensaciones de dicha sino también episodios que permiten fijar el origen de traumas personales bien conocidos:

Recuerdo cómo para mi madre no había nada más insoportable que la molestia de que al caminar yo siempre fuera medio paso detrás de ella. Parecer más lento, más torpe, más tonto de lo que era: esta costumbre la adquirí en esos paseos que hacíamos juntos, y tiene el gran peligro de creerse uno más rápido, más hábil y más listo de lo que es (Benjamin, 1996, p. 190).

$\mathrm{Al}$ igual que sucede con su dificultad para orientarse debidamente, la lentitud y el embobamiento, lejos de ser disfuncionales, se convierten en claves de una epistemología genuina. La infantilización inducida a partes iguales por la ausencia de obligaciones, las elementales condiciones de vida y la virginidad de la isla obran la maravilla de abrir la caja negra de la memoria y rescatar una niñez que en realidad, para un Benjamin tan inadaptado al pragmatismo del mundo adulto como devoto de los objetos fabulosos, los juegos del lenguaje y los libros infantiles, nunca quedó atrás. Si en palabras de Miguel Morey "el paseante siempre pasea con un niño, es siempre el niño que fuimos quien pasea" (2015, p. 338), qué decir del individuo Benjamin en ese cruce entre diván expandido y salón de juegos que es la naturaleza ibicenca, donde toda dialéctica y toda proyección de futuro se hallan verdaderamente en suspenso. "Lo más importante para el autor que recuerda no es lo que ha vivido, sino el proceso mismo en el que se teje su recuerdo, ese largo trabajo de Penélope que es el recordar” (Benjamin, 2008a, p. 317), y no habiendo mejor lugar para desarrollar la tarea, esta se prolongará a lo largo de su primera estancia y se convertirá ella misma en un no parar:

El que un buen día ha empezado a abrir el abanico del recuerdo, ese siempre encuentra nuevas piezas, nuevas varillas; ninguna descripción le satisface, pues se ha dado cuenta de que cabría desplegarla, de que únicamente en los pliegues reside lo auténtico: aquella imagen, aquel sabor, aquel tacto a causa del cual hemos desdoblado, hemos desplegado todo esto, y entonces el recuerdo va de lo pequeño a lo pequeñísimo, de lo pequeñísimo a lo ínfimo, y cada vez se hace más fuerte aquello con lo que se encuentra en estos microcosmos (pp. 191-192).

Aunque la portabilidad de ese microcosmos va de suyo, dada su calidad mental, desde el primer momento encontrará además forma física en uno de los cuadernos de setenta y ocho páginas en octavo menor en los que tanta escritura, igualmente microscópica, era Benjamin capaz de insertar ["redactó estos apuntes de manera fragmentaria, con extraordinaria rapidez y caligrafía apenas legible", observa Scholem al respecto (2003, p. 183)]. De este modo, tras abandonar la isla continuará viajando de un lugar a otro -Niza, donde planea en firme quitarse la vida, el balneario de Poveromo, nuevamente París- acompañado de un proyecto y de un cuaderno que irá mimando al 
calor de "expediciones en las profundidades de la memoria" (Benjamin y Scholem, 1987, p. 27) dotadas de carácter y provecho muy dispar. Como era de esperar a la luz de las circunstancias vitales y de la propia sustancia del material, la pretendida continuidad de Crónica de Berlín se romperá finalmente en imágenes volanderas de distinta entidad, a saber, las treinta piezas que enviará al domicilio de Scholem en Jerusalén en febrero de 1933, coincidiendo con la subida de Hitler al poder - es célebre la obsesión de Benjamin por poner a salvo sus manuscritos antes que a sí mismo-, y que en parte verán la luz en publicaciones periódicas alemanas, bajo seudónimo y sin remuneración.

Si los fragmentos de vida contenidos en Infancia en Berlín hacia 1900 son en buena medida el resultado de la indagación mnésica llevada a cabo en sus garbeos por la isla, la Serie de Ibiza -publicada en el Frankfurter Zeitung cuando aún permanece en ella-contiene la primera manifestación literaria de esas caminatas, con alusión incluida a la confusión temporal y mental propia del paseante extremo:

Quien asciende solo a una montaña y finalmente llega arriba agotado, para bajar después con unos pasos que hacen estremecer todo su cuerpo, siente cómo el tiempo se relaja, su estructura interior se desmorona y atraviesa el asfalto del instante como si fuera en sueños. Algunas veces trata de quedarse de pie pero no lo consigue. Y, ¿quién sabe si lo que le estremece son pensamientos o el áspero camino? Y ahora su cuerpo es un caleidoscopio que le va mostrando a cada paso las figuras cambiantes de que se compone la verdad (Benjamin, 2019, p. 359).

Este relativismo sensorial porta ecos de sus experiencias y escritos de juventud pero se corresponde también con el tono de los relatos redactados al hilo de su experiencia pedestre en la isla, con un puñado de textos que ya en su formato episódico y en su título genérico, Sombras breves, parecen remitir a la frágil calidad de lo pasajero.

Contra todo pronóstico, sin embargo, cuando en abril de 1933 Benjamin regrese a la isla con la intención de propiciar una nueva Schicksalpause o cesura del destino ${ }^{1}$ y alentar así su creatividad, a su recién estrenada condición de exiliado biopolítico añadirá el desencanto de no hallar ni el ambiente ni la acogida de la primera vez, a tal punto que su "arraigado recelo hacia la colonización del campo" le hará desear "las densas sombras con las que las alas de la crisis económica enterrarán en pocos años toda esta soberbia de tenderos y veraneantes" (Benjamin, 2008b, p. 210). Problemas de todo tipo le llevarán a emplear la Naturaleza no ya como marco de evocación o esparcimiento sino como un lugar de trabajo íntimo, casi secreto:

\footnotetext{
${ }^{1}$ Es evidente que la característica vis melancólica de Benjamin aprecia, en sus periodos de asueto ibicenco, lo que alguna vez definiera como "una de esas pausas del destino en las que más tarde descubrimos que contenían el germen de un curso completamente diferente del que de hecho nos ha caído en suerte" (Benjamin, 2010, p. 321). 
Me levanto, así pues, a las 6:30, algunas veces incluso a las 6, y a las siete me dirijo a la pendiente de alguna montaña, en donde busco mi tumbona, allí escondida. Luego, a eso de las 8 descorcho, como algún aprendiz de albañil o picapedrero, el termo y me dispongo a tomar mi desayuno. Tras eso trabajo y leo hasta la una (p. 178).

Aunque no parece haber ahora grandes desniveles, riesgo de caída ni posibilidad de pérdida, eternas amenazas del ánimo benjaminiano, es sabido que la Naturaleza se las ingenia para acabar cobrándose de uno u otro modo su pieza ["en estas tardes a mediodía siempre sopla un viento tan fuerte que, a pesar de que he desarrollado todo un virtuosismo técnico al respeto, soy incapaz de sostener las hojas grandes o las pequeñas para escribir"' (p. 155)], y poner a cada cual donde le corresponde - "he trasladado hoy mi trabajo de escritura a un café; no muchas ventajas tenía mi escondite en el bosque", reconoce en una carta a Gretel Karplus, esposa de Adorno (p. 175).

En su huida de las inclemencias meteorológicas a campo abierto la vieja higuera frente a la casa será a menudo su mejor aliada, y todo indica que justamente ahí tendrá la oportunidad de asistir al paso de quien, apenas ocho años después, se acabará convirtiendo en el peor de los posibles, nada menos que el general Francisco Franco (véase Valero, 2001, pp. 93-95). La coincidencia es, en verdad, extraordinaria: el 6 de mayo de 1933, recién nombrado comandante militar de Baleares, Franco gira una visita a la isla y pasa revista al faro de Coves Blanques, situado a apenas doscientos metros de la casa donde reside un Benjamin que a la sazón cuenta su misma edad. Es poco probable que la aparatosa comitiva, encargada de contrastar in situ el valor estratégico de la bahía -y tienta pensar que Franco, animado por el reciente triunfo del nazismo, planeaba ya el golpe militar que desencadenaría la Guerra Civil Española pocos años después-, pasara inadvertida para un Benjamin que trabajaba a la intemperie junto a la carretera. Aunque en ninguna de sus cartas deje constancia de la visión de ese Malach ha-mavis, el ángel de la muerte en la tradición judía, todo indica que desde ese mismo lugar remitirá un mes después estas angustiosas palabras a Gershom Scholem, como si la oscura anunciación se las hubiera dictado: “¿existe para mí (para lo que yo puedo y mis conocimientos) más espacio que en Europa? Si no hay más, entonces hay menos. Esta frase no precisa explicación" (Benjamin, 2008b, p. 213). Sabemos ahora de qué manera Franco y el modelo totalitario al que se adscribía su régimen pondrían fin a las dudas del filósofo alemán: achicando aún más ese espacio y conduciéndole a lo que él mismo calificará en su última carta como "una situación sin salida" (Adorno y Benjamin, 1998, p. 325) de la que, abatido por años de pesadumbre y penurias, no supo o no quiso escapar ${ }^{2}$.

\footnotetext{
${ }^{2}$ Tras haber recorrido clandestinamente y con enormes dificultades una antigua senda de contrabandistas que unía Francia y España por de la vertiente mediterránea del Pirineo, Walter Benjamin se quitaba la vida la noche del 26 de septiembre de 1940 al ver denegada su solicitud de entrada en territorio español. Siendo su intención atravesar la península para embarcarse en Lisboa con rumbo a Estados Unidos, la prohibición oficial implicaba 34 | AlPha No49 (DiCIEMBRE 2019) PÁGS. 25-37. ISSN 07 16-4254
} 
No deja de ser una terrible paradoja que el último viaje de Benjamin discurriera por un paraje poblado de vegetación casi análoga a la ibicenca y bordeado por el mismísimo mar. En ese marco escénico, la tan traída noción de aura cumple un papel nada desdeñable porque el camino que le condujera por el Pirineo funcionaría, en buena medida, como aquellos pasajes parisinos por los que transita el individuo alienado sin entrar en contacto físico con los elementos dispuestos a su paso: lo que en ellos son mercancías refulgiendo tras los escaparates como intocables objetos de culto, en el estrecho sendero de montaña correspondería a un sinfín de formas naturales por las que apenas puede uno, abrumado como está por las circunstancias, deslizar la mirada (véase De Luelmo, 2010, p. 25-31). Sucede, además, que Benjamin da en explicar el abstruso concepto de aura sometiéndolo a fricción con su contrario, uno de índole estrictamente física y de gran relevancia en todo ese trance, el de huella: "la huella es la aparición de una cercanía, por lejos que pueda estar lo que la dejó atrás; el aura es la aparición de una lejanía, por cerca que pueda estar lo que la provoca. En la huella nos hacemos con la cosa; en el aura es ella la que se apodera de nosotros" (Benjamin, 2005, p. 450).

Efectivamente, el aura del paisaje mediterráneo acabaría tomando posesión del alma benjaminiana y haciéndola colapsar por entero: si con ligeras variaciones todo se repite siempre dos veces, según había anotado el filósofo al término de su ibicenco $A l \mathrm{sol}$, y si ese lema hasídico resulta aplicable a la analogía entre pasaje urbano y pasaje pirenaico - tal y como se acaba de hacer aquí-, tanto más puede aplicarse a la parálisis inducida por la Naturaleza. "Y allí se nos ofreció una imagen de una perfección tan inmóvil que tuvo lugar en mí algo extraño, pero no incomprensible: en realidad no veía absolutamente nada" (Benjamin, 2008b, p. 206), confesaba a Gretel Karplus al hilo de una sublime excursión por la zona más agreste de Ibiza, en junio de 1933; llegado ese mal día de 1940, el 26 de septiembre, aquel colapso extático ante el paisaje se convertiría en otro muy distinto, pues según relata Grete Freund -una de las migrantes ilegales que le acompañaba-, "Benjamin estaba ya muy fatigado cuando sufrió una crisis cardiaca en el camino" que se adelantaría en pocas horas al desenlace definitivo (testimonio recogido en Benjamin, 2005, p. 976). De igual modo, si en 1933 anotaba el filósofo con indisimulada satisfacción que acababa de cubrir "catorce horas de marcha con mis amigos franceses" (2008b, p. 210), ninguna pudo mostrar ese día de 1940, cuando una ruta de idéntica duración ["nos llevó 14 horas sin encontrar posibilidad de comer o de beber" (testimonio citado)], le condujo a la pequeña población costera de Portbou, estación término de su existencia. Muchos kilómetros recorridos desde la infancia quedaban atrás en ese momento, muchos pasos que alternaban aura y huella y contenían

ser devuelto a las autoridades aduaneras de la Francia ocupada y, con toda probabilidad, su entrega a la Gestapo y la inmediata deportación a un campo de exterminio. 
en filigrana aquella alianza de carácter y destino sobre la que Scholem iba a reflexionar de nuevo al hilo de los paseos compartidos:

A veces hacíamos excursiones, como una marcha nocturna que emprendimos a finales de mayo de 1918, desde Thun hasta Interlaken. Caminábamos en silencio; cuando comenzábamos a hablar, Benjamin no tardaba en detenerse, gesto que era en él un signo de deferencia [...] Fue en esas conversaciones cuando por vez primera me llamaron la atención los entonces incipientes, pero más tarde acusadamente desarrollados, rasgos depresivos de Benjamin, su carácter fundamentalmente melancólico (2003, p. 78).

A la vista de lo expuesto en las páginas anteriores sabemos que ese temperamento alentó buena parte de sus escritos acerca de la Naturaleza pero también que acabaría siendo, tras la angustiosa odisea en que esta le puso a prueba, la más exigente de todas, decididamente fatal. La tensión acumulada desde la infancia se rompía finalmente en ese punto y dejaba tras de sí un rastro de experiencias y reflexiones que invita aún a ser recorrido, pues, a pesar de su dispersión aparente, a pesar también de su variable interés, articula un camino rebosante de sentido y abierto al paso a perpetuidad.

\section{OBRAS CITADAS}

Adorno, Theodor; Benjamin, Walter (1998). Correspondencia 1928-1940. Madrid: Trotta (trads. Jacobo Muñoz y Vicente Gómez).

Benjamin, Walter (2010). Obras, IV, 1. Madrid: Abada (trad. Jorge Navarro).

— (2008a). Obras, II, 1. Madrid: Abada, 2008 (trad. Jorge Navarro). (2008b). Cartas de la época de Ibiza. Valencia: Pre-textos (trads. Germán Cano y Manuel Arranz).

— (2005). Libro de los Pasajes. Madrid: Akal (trads. Luis Fernández, Isidro Herrera y Fernando Guerrero).

_ (1996). Escritos autobiográficos. Madrid: Alianza (trad. Teresa Rocha). (1972). Gesammelte Schriften, I. Fráncfort del Meno: Suhrkamp.

Benjamin, Walter; Scholem, Gershom (1987). Correspondencia 1933-1940. Madrid: Taurus (trad. Rafael Lupiani).

De Luelmo, Chema (2010). Unterwegs. Al paso de Walter Benjamin. Madrid: Maia.

De Paz, Alfredo (1992). La revolución romántica. Poéticas, estéticas, ideologías. Madrid: Tecnos (trad. Mar García).

Marx, Karl (2005). Manuscritos de economía y filosofía. Madrid: Alianza (trad. Francisco Rubio).

Morey, Miguel (2015). Pequeñas doctrinas de la soledad. Madrid: Sexto Piso. 
Schelling, Friedrich W. J. (1996). Escritos sobre filosofia de la naturaleza. Madrid: Alianza (trad. Arturo Leyte).

Schlögel, Karl (2007). En el espacio leemos el tiempo. Sobre Historia de la civilización y Geopolítica. Madrid: Siruela (trad. José Luis Arántegui).

Scholem, Gershom (2003). Walter Benjamin y su ángel. Buenos Aires: Fondo de Cultura Económica (trads. Ricardo Ibarlucía y Laura Carugati).

— (1987). Walter Benjamin. Historia de una amistad. Barcelona: Península (trad. Vicente Jarque).

Taylor, Charles (1996). Fuentes del yo. La construcción de la identidad moderna. Paidós: Barcelona (trad. Ana Lizón).

Valero, Vicente (2001). Experiencia y pobreza. Walter Benjamin en Ibiza, 1932-1933. Barcelona: Península. 